\title{
GROWING WALLEYE FINGERLINGS IN SMALL LAKES
}

WEN K. LIAW, Saskatchewan Fisheries Laboratory, Department of Tourism and Renewable Resources, 30 Campus Drive, Saskatoon, Saskatchewan. S7N 0X1

Saskatchewan has about 94 thousand lakes which cover about $13 \%$ of the province surface area. Only a small portion (perhaps not more than $10 \%$ ) of these lakes are readily accessible. There are some 14 hundred commercial fishermen and over 230 thousand active anglers who fish in the province. They take a total of close to 10 million $\mathrm{kg}$ of fish annually, contributing significantly to the provincial economy.

Growing fishing pressure, particularly from an increasing number of anglers, together with other factors such as pollution and habitat loss, have created problems in a number of lakes. A decline, and in some cases a collapse, in the stocks of walleye - the most sought-after game fish - in the more heavily-fished lakes has taken place in recent years.

The Fisheries Branch of the Department of Tourism and Renewable Resources has attempted to bolster the declining fish stocks by stocking fry straight from the hatchery into the lakes. The results have not always been satisfactory; predation by existing fish and competition for food are possible causes of massive fry mortalities. On the other hand, it has been demonstrated that production of walleye stocks can be successfully maintained or enhanced by planting rearing-pond-grown fingerlings rather than fry (e.g. in Minnesota and Wisconsin). The fry have a better chance of surviving if they are first raised in small, fertile and predatorfree natural lakes or man-made ponds before being released into the problem lakes.
The Fisheries Branch initiated a pilot project two years ago to test the feasibility of growing walleye from fry to fingerlings in ponds or small lakes for later transfer into problem lakes. This article summarizes the major findings of the project.

\section{The Rearing Ponds}

As shown in Figure 1, the lakes used as rearing ponds fall into two geological regions: the shield-boundary (Ponds 1 4) and the sedimentary (Ponds 5-7). These ponds were selected mainly for their relatively small size (less than 24 ha, except Pond 4 which is 169 ha), shallow depth (maximum less than $3 \mathrm{~m}$ ) and proximity to the problem lakes.

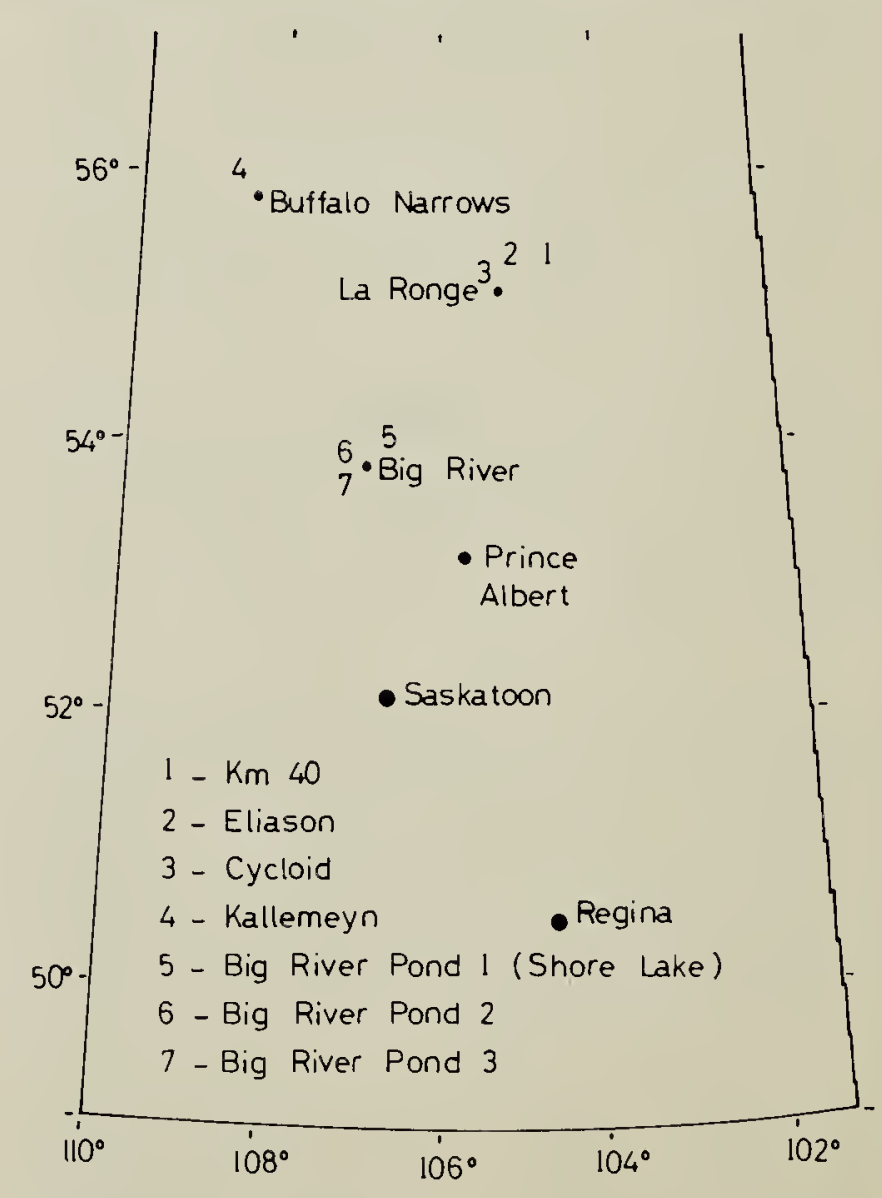

Figure 1. Location of the walleye rearing ponds. 
Surface water temperatures during the period May-August ranged from 10 to $26^{\circ} \mathrm{C}$ with averages of $16-20^{\circ} \mathrm{C}$. The ponds warm up earlier and faster than adjacent larger lakes in the spring - an advantage to fry stocking.

There appeared to be abundant zooplankton (food for fry and fingerlings) in all ponds except Pond 5. The luxurious growth of submerged weeds in this pond seemed to have suppressed the growth of algae, resulting in a low production of zooplankton.

There were no native fish in the three ponds at La Ronge. Numerous Brook Sticklebacks were found in Pond 4, while Fathead Minnows in addition to sticklebacks were present in Pond 5. However, due to severe winterkill, these fish were nearly wiped out in 1982.

\section{Stocking of Fry}

Walleye fry newly hatched at the Qu'Appelle Fish Culture Station or the Lynx River Hatchery (north of La Ronge) were used for stocking the rearing ponds. The stocking was done in late May to early June. The rate of stocking varied from 600 to 6,000 fry/ha with an average of $3,140 \mathrm{fry} / \mathrm{ha}$.

\section{Food of Fingerlings}

The diet of walleye fingerlings differed from one pond to another, depending on the availability of food organisms. It appeared that larvae and pupae of chaoborus and cladocerans were the most frequently eaten food items. The number of chaoborus larvae ingested by a large fingerling (around $144 \mathrm{~mm}$ fork length, from nose tip to base of tail fork) could be as many as 454 individuals.

In addition to chaoborus and cladocerans, organisms such as amphipods, beetle larvae, mayfly larvae, back swimmers and sticklebacks were found in the diet of larger fingerlings.
The food condition in these ponds was generally good, as an average of $78 \%$ of the total number of fish examined for diet contained food in their stomachs.

\section{Growth and Production}

The growth of walleye in these rearing ponds was generally rapid. In 60 days, the fry had reached an average of 80-90 $\mathrm{mm}$ in fork length and about $6 \mathrm{~g}$ in weight. By the end of the summer, an average size of $120-130 \mathrm{~mm}$ and $18-20$ $\mathrm{g}$ was attained.

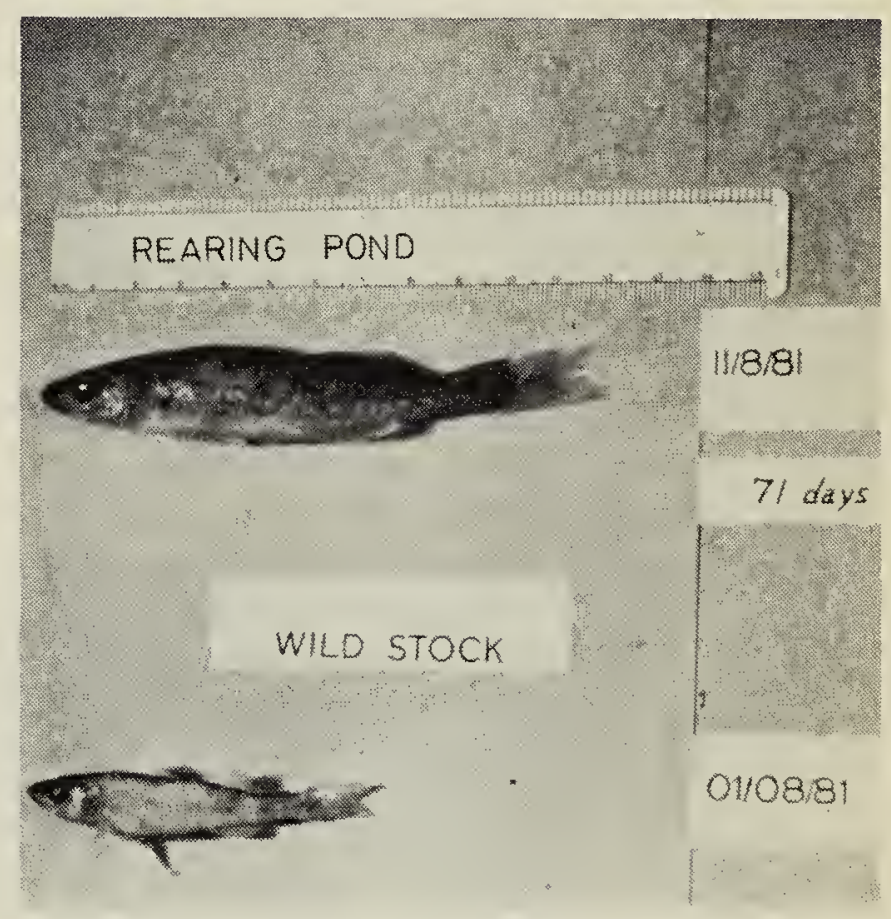

A comparison of rearing-pond grown and wild stock walleye fingerlings.

Measurements suggest that the fingerlings grew fast up to about $70-80$ days after stocking. Beyond this period (usually between the end of July and the middle of August), the rate of increase in length began to taper off. However, continuous good growth was possible if food organisms were still plentiful in the pond. 
The practical implication of the above findings on growth pattern is that there is little to be gained by keeping the fingerlings in the pond for more than approximately 80 days. Beyond this period, the fingerlings increase very little in length and much less in weight due to lack of food; thus, higher fingerling mortalities may be expected. Furthermore, larger lakes usually have abundant forage fish (e.g. perch and minnows) which is an excellent food source for the newly-released fingerlings. By changing from an invertebrate diet (in the pond) to a fish diet (in the lake), the fingerlings can keep on growing until the end of the summer. Being usually larger than the native fingerlings, the rearing-pondgrown walleye should have no problems in competing for food.

The survival of walleye in six of the rearing ponds from fry to fingerlings varied considerably from pond to pond and year to year. It varied from nearly zero to $16 \%$ (average $7 \%$ ) which is poor but within the range expected for natural rearing ponds. Similarly, the density of the fingerlings, ranging from almost zero to $655 \mathrm{fish} / \mathrm{ha}$, is low compared with figures from Minnesota (normal density around 19.4 thousand fish/ha) and Manitoba (average 900 fish/ha), but expected for natural rearing ponds. At an average weight of $5 \mathrm{~g}$ near the end of July, the highest density in Saskatchewan gives a fingerling production of $3.3 \mathrm{~kg} / \mathrm{ha}$, but this is not the highest yield in weight. A small fertile pond at Big River producing $14 \mathrm{~kg} / \mathrm{ha}$ of fingerlings (density 468 fish/ha) in early September was the most productive rearing pond.

A total of 5,902 fingerlings were harvested from six of the ponds in both years. Of these, 3,942 were restocked into Lac La Ronge and 1,960 were transferred to Delaronde Lake. Harvesting was done by trapping, except for Pond 5 where the fingerlings were drained into Delaronde Lake via a newly-constructed channel. The recovery of fingerlings varied from 10 to $93 \%$ (average $57 \%$ ), depending on the fishing intensity.

\section{Conclusions}

This project has demonstrated that it is feasible to grow walleye from fry to fingerlings in natural ponds in central and northern Saskatchewan. Growth was excellent, but recovery could have been better.

The poor recovery of the walleye in one pond (No. 5) in 1981 was probably caused by the lack of spring zooplankton blooms and the predation by the abundant sticklebacks and minnows. Therefore, native fish, if present, should be eradicated before fry stocking. This can be done by drawing down of pond water in the fall to ensure a winter-kill. The presence of numerous predaceous beetle larvae in all ponds might be partly responsible for the generally low recovery. The control of the predaceous insects is more difficult. However, measures used effectively elsewhere (e.g. using coal oil) should be tested for Saskatchewan situations, if possible. Furthermore, in order to have an adequate supply of food organisms for the fry, only naturally fertile lakes should be used as rearing ponds. Fertilization to promote zooplankton blooms in the spring will be necessary if a pond is not fertile, but otherwise suitable.

Since the completion of this project, several rearing ponds have already been set up for the production of walleye fingerlings. Although the enhancement program has moved from pilot to production phase, experiments are still required to test certain pond management techniques in order to maximize fingerling production. Also, the contribution of the fingerlings released for the restoration of depleted walleye populations needs to be monitored and assessed in the future. 